\title{
Unprovoked internal jugular vein thrombosis: a case report and literature review
}

Loïc Payrard', Léa Iten'1, Jacques Donzé ${ }^{1,2,3}$ and Gregor John ${ }^{1,4^{*}}$ (D)

\begin{abstract}
Background: Managing thrombosis in rare sites is challenging. Existing studies and guidelines provide detailed explanations on how to overcome lower-limb thromboses and pulmonary embolisms, but few studies have examined thrombosis in rare sites. Lack of data makes clinical practice heterogeneous. Recommendations for diagnosing, treating, and following-up internal jugular vein thrombosis are not clearly defined and mostly based on adapted guidelines for lower-limb thrombosis.
\end{abstract}

Case presentation: A 52-year-old Caucasian woman came to the Emergency Department with chest, neck, and left arm pain. Computed tomography imagery showed a left internal jugular vein thrombosis. An extensive workup revealed a heterozygous factor $\vee$ Leiden gene. Therapy was initiated with intravenous unfractionated heparin, then switched to oral acenocoumarol, which resolved the symptoms. Based on this case presentation and a literature review, we summarize the causes, treatment options, and prognosis of unprovoked internal jugular vein thrombosis.

Conclusions: Managing internal jugular vein thrombosis lacks scientific data from large randomized clinical trials, partly because such thromboses are rare. Our literature review suggested that clinical treatments for internal jugular vein thrombosis often followed recommendations for treating lower-limb thrombosis. Future specific studies are required to guide clinicians on the modalities of diagnosis, screening for thrombophilia or oncologic disease, treatment duration, and follow-up.

Keywords: Internal jugular vein, Thrombosis, Thrombophilia, Unprovoked

\section{Background}

Thromboembolic disease is the third most frequent cardiovascular disease [1]. It has been thoroughly studied in recent decades, resulting in a standard diagnostic strategy, international guidelines, and new medications $[2,3]$.

There is scarce medical literature available on unprovoked internal jugular vein (IJV) thrombosis, essentially just case reports and short case series. IJV thrombosis is, therefore, often managed with reference to guidelines dedicated to

\footnotetext{
*Correspondence: gregor.john@rhne.ch

'Department of Internal Medicine, Neuchâtel Hospital Network, Rue de la Maladière 45, CH-2000 Neuchâtel, Switzerland

${ }^{4}$ Department of Internal Medicine, Geneva University Hospitals (HUG), Gabrielle-Perret-Gentil 4, CH-1205 Geneva, Switzerland

Full list of author information is available at the end of the article
}

thromboses occurring in more common sites, notably the deep veins of the lower limbs [2, 3]. Yet unusual thrombosis sites are associated with distinct risk factors and complications, and some treatments (e.g. direct oral anticoagulants) have not been tested specifically. Thus, we believe that specific recommendations are needed to guide the treatment management of patients with thromboses in uncommon sites.

This report describes a case of unprovoked IJV thrombosis and an accompanying literature review about diagnosing and treating this condition.

\section{Case presentation}

A 52-year-old Caucasian woman under treatment for hypothyroidism arrived at the Emergency Department with 
constrictive chest pain that had been radiating into her left arm and cervical region for 1 week, accompanied by newonset dyspnea which had worsened 2 days before her medical visit. Her physical examination was unremarkable, except for high blood pressure $(188 / 104 \mathrm{mmHg})$ and excess weight (body mass index $=28 \mathrm{~kg} / \mathrm{m} 2$ ); a blood test showed a high D-dimer concentration $(2170 \mu \mathrm{g} / \mathrm{l})$. A computed tomography $(\mathrm{CT})$ scan performed to exclude pulmonary embolism was inconclusive. However, fat infiltration around the left jugular-carotid led to a further investigation using neck ultrasound. This showed a thrombosis emerging from the base of the left subclavian vein and extending 11 centimeters into the IJV, sparing the cerebral vessels.

The patient described spontaneous hair loss and a 10 $\mathrm{kg}$ gain in weight over the previous year. She was taking levothyroxine but took no other medication or hormonal substitutes. There was no history of smoking, recent surgery, trauma, infectious disease, intravenous medical or recreational drug use, or past catheter insertion.

A chest CT scan and a colonoscopy revealed no cancer. A recent gynecological check-up consisting of a physical examination, a mammography, and a Pap smear found no pathology. A thyroid-stimulating hormone test and urinary cortisol were normal. Because of the patient's young age and no obvious risk factor for thromboembolic disease, we completed the investigations with a thrombophilia workup. Antinuclear antibodies were positive at 1:320, but without other criteria suggesting overt lupus [4]. Otherwise, antinucleoprotein antibodies (SSA, SSB, RNP, Sm, Scl70, Jo1), antinucleosome antibodies, anticardiolipin antibodies, and anti-B2-glycoprotein antibodies were negative. We did not test for lupus anticoagulant due to the patient's anticoagulation treatment and the risk of a false-positive [5]. Antithrombin, protein $\mathrm{C}$, and protein $\mathrm{S}$ activity were within the normal ranges and were tested before the introduction of anticoagulant treatment. Only a heterozygous factor V Leiden gene (R506Q) was found positive. We concluded on the diagnosis of an unprovoked IJV thrombosis.

After 5 days of intravenous unfractionated heparin, symptoms rapidly regressed, allowing a switch to an oral anticoagulant (acenocoumarol). The patient was discharged home 1 week after admission. After 3 months, the decision to continue anticoagulation with acenocoumarol was taken according to European Society of Cardiology guidelines [2] for patients over 50 years old with unprovoked thrombosis and a low risk of major bleeding (HAS-BLED score for major bleeding risk $=1$ due to hypertension, corresponding to a 3.4\% risk [6]). 6 months after Emergency Department admission, the patient was symptom-free.

\section{Discussion and conclusions}

We have described a patient presenting with unprovoked IJV thrombosis, heterozygous factor V Leiden gene, and no other obvious risk factors. This rare thrombosis site reveals the limits of international guidelines based on large, randomized clinical trials mainly designed for deep-vein thrombosis in a limb or pulmonary embolism. There is, therefore, a lack of evidence which might guide clinicians in their workup and treatment of thrombosis in rare sites. Although, by their very nature, published case reports and case series provide biased information, exploring similar cases can be a first step (and sometimes the only one possible) towards collecting scientific evidence.

\section{Medline research strategy}

We searched Medline using the keywords (spontaneous OR unprovoked OR idiopathic OR primary AND internal jugular vein thrombosis AND English) and excluded reports of provoked IJV thrombosis to collect information on causes, treatment modalities, and complications. We retrieved 40 relevant articles in English (Table 1). These articles included 48 patients with unprovoked IJV from 17 countries, but mostly from Japan (9/40 articles). More than a third $(17 / 48 ; 35 \%)$ were still truly idiopathic after the workup (Table 2).

\section{Internal jugular vein thrombosis epidemiology}

Upper-limb thrombosis accounts for a maximum of $10 \%$ of all deep-vein thromboses [2, 47]. IJV thrombosis is even less frequent, but epidemiological studies are lacking (other unusual sites for thrombosis, such as the mesenteric vein, account for $0.002-0.006 \%$ of all inpatient admissions) [48] Overall, the most common causes of IJV thrombosis are cancer, central venous catheter placement, and ovarian hyperstimulation syndrome (OHS) [26]. IJV thrombosis can be provoked or unprovoked. The former accounts for four out of five cases [26]. Most IJV thromboses are secondary to central catheter or pacemaker placement, extrinsic compression (by a tumor or malformation), local infections (e.g., Lemierre disease), cervical trauma, or ENT cancer. Unprovoked IJV thrombosis is uncommon and has been associated with paraneoplastic disease, thrombophilia, OHS, and idiopathic IJV [10, 26, 49-51]. OHS is associated with thromboembolic complications, but their mechanisms are incompletely understood [52]. In addition to the usual hemostatic changes during pregnancy [53], OHS can cause increased levels of coagulation factors [54].

\section{Clinical presentation}

The spectrum of potential clinical presentations is broad, ranging from asymptomatic disease to diffuse and nonspecific pain. Neck pain and swelling are the most frequent symptoms, found in $24 / 48$ patients (50\%). IJV thrombosis is a serious event, with a potentially fatal outcome, but complications in IJV thrombosis have seldom been reported [55]. Pulmonary embolism was reported in 3 cases (6\%). Surprisingly, there were no cases describing 


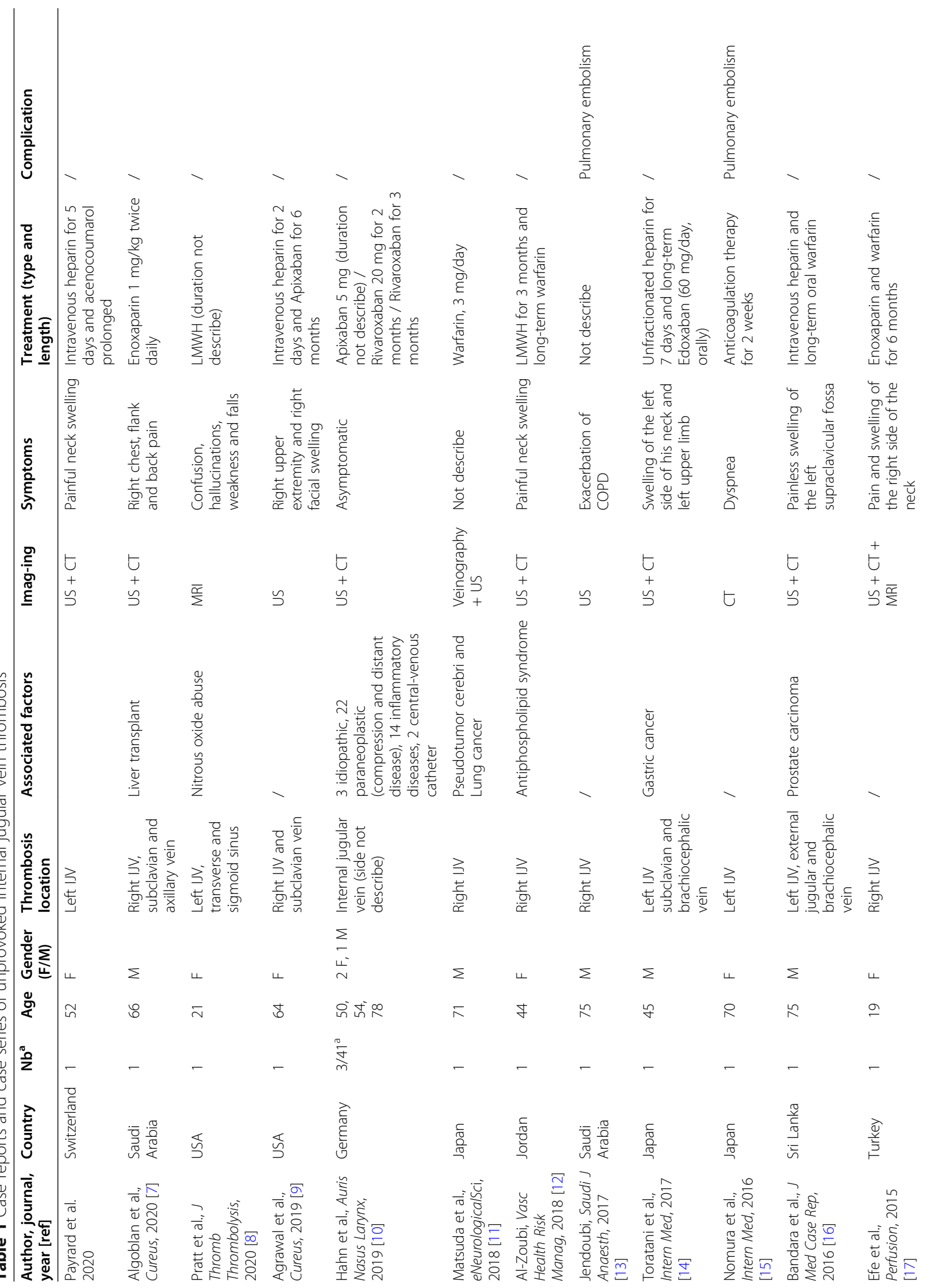




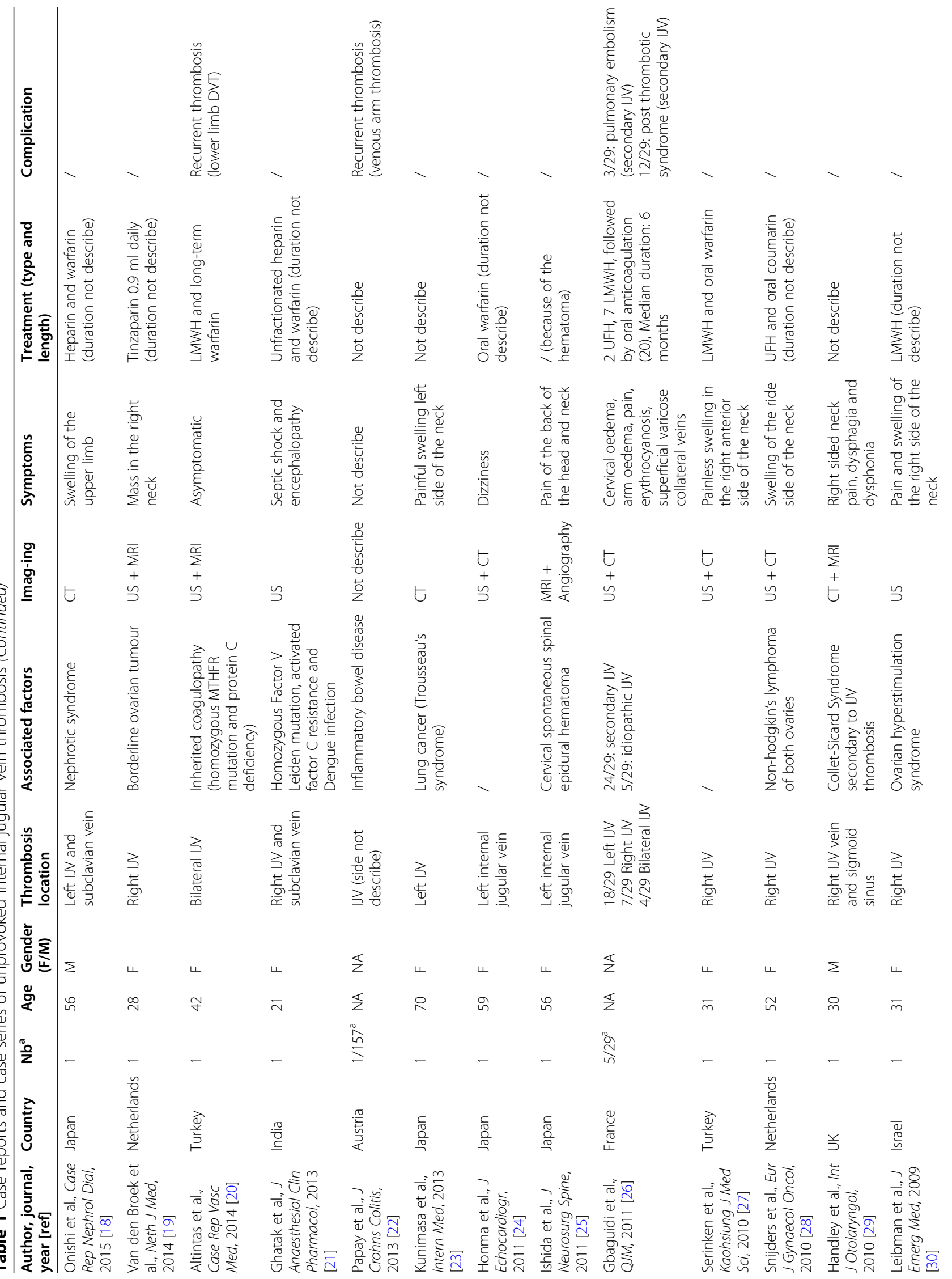




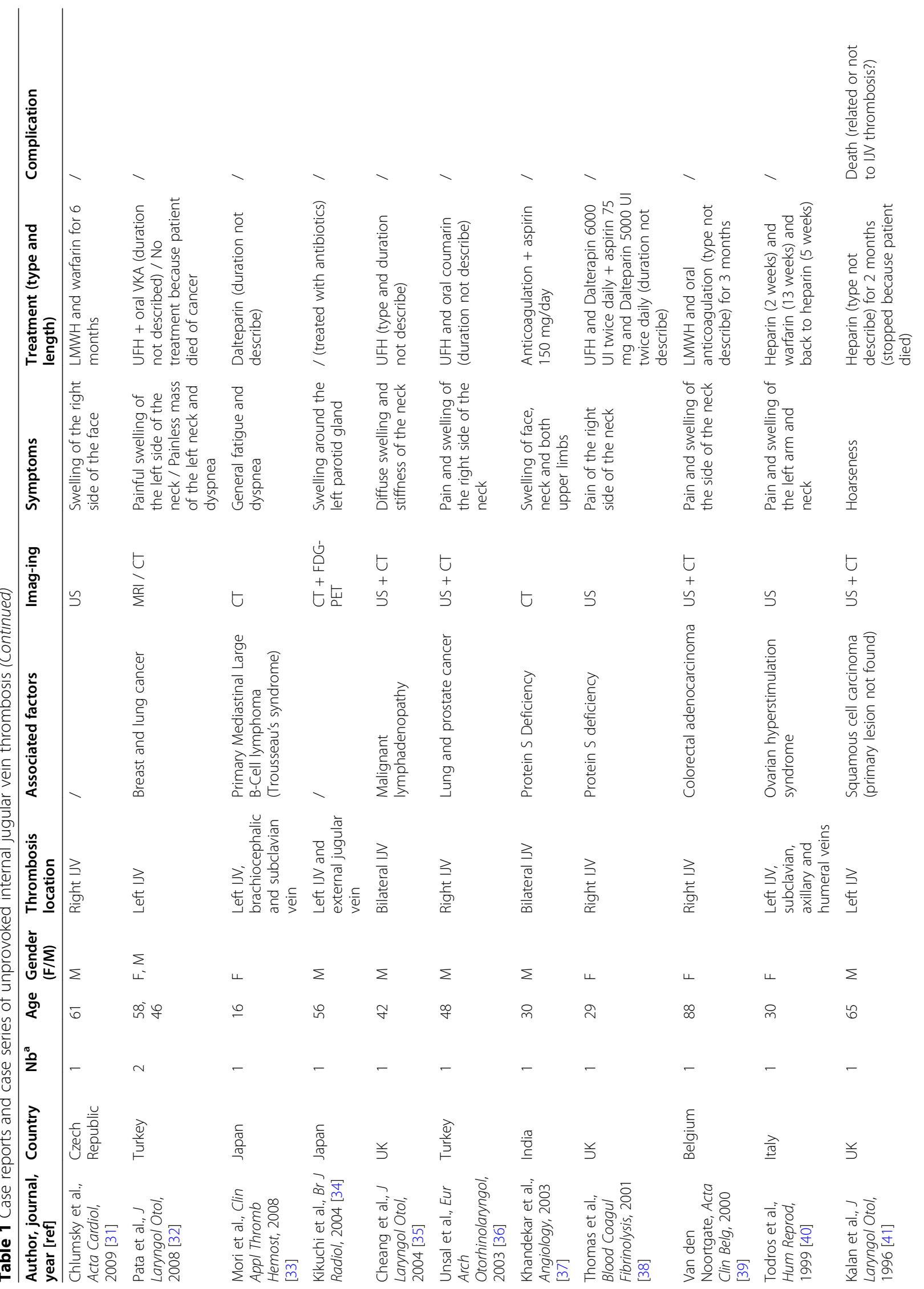




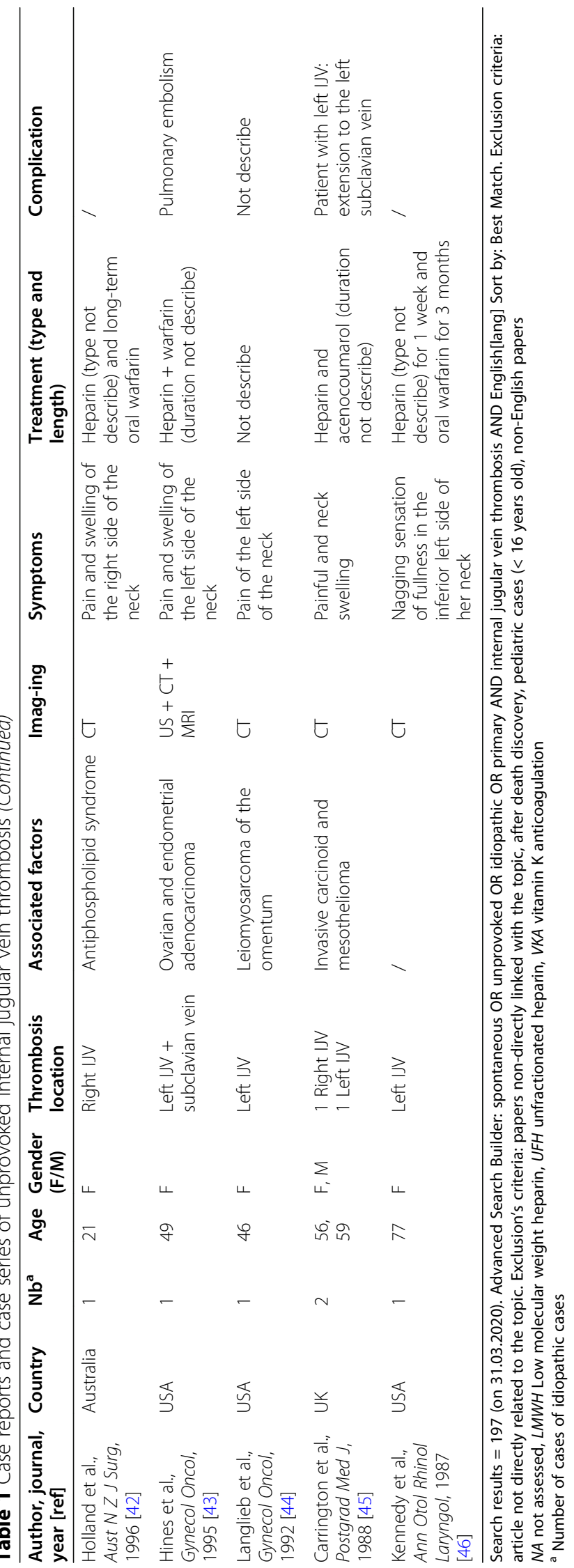


Table 2 Etiologies of patients $(N=48)$ diagnosed with unprovoked IJV (based on a literature review)

\begin{tabular}{ll}
\hline Etiology & Number (\%) \\
\hline Idiopathic & $17(35.4)$ \\
Paraneoplastic disease & $16(33.3)$ \\
Coagulopathy & $4(8.3)$ \\
Ovarian hyperstimulation syndrome (OHS) & $2(4.2)$ \\
Antiphospholipid syndrome & $2(4.2)$ \\
Other causes & $7(14.6)$ \\
\hline
\end{tabular}

neurological complications. The risk of recurrent IJV thrombosis is unknown since the follow-up of published cases was generally interrupted after 3 to 6 months (Table 1).

\section{Diagnostic testing}

D-dimer concentrations have excellent negative predictive value, even for deep-vein thrombosis of the upper extremities. However, D-dimer concentrations have not been validated with IJV thrombosis because of the lack of prospective outcome trials. Lower D-dimer sensitivity in IJV thrombosis could be an issue, resulting in higher false-negative rates, which could lead to fatal consequences $[56,57]$.

Performance of imaging to diagnosis IJV is unknown. The majority of reports used ultrasonography often completed with CT $(21 / 48 ; 43.8 \%)$. In cases of unprovoked IJV thrombosis, oncological disease and thrombophilia should be screened for since they are more common than in cases of lower-body thrombosis. Indeed, these conditions are frequently associated with IJV thrombosis (Table 2).

Thrombophilia is defined as a hereditary or acquired genetic abnormality predisposing the patient to thromboembolic events [58]. The F5 R506Q gene (the factor $\mathrm{V}$ Leiden mutation) is the most common prothrombotic gene mutation in Caucasians [59], affecting $3-7 \%$ of this population. It is a gain-of-function mutation in the procoagulant factors. The annual incidence of venous thromboembolism (VTE) in heterozygous carriers of the factor $\mathrm{V}$ Leiden mutation is approximately $0.45 \%$ [60].

Middeldorp et al. recommended not routinely screening for hereditary thrombophilia as it does not affect most patients' clinical management, and long-term anticoagulation is generally recommended for patients with unprovoked thrombosis [58]. Thrombophilia screening is only recommended for young (age $<50$ ) patients with a VTE, in cases of recurrent VTE, and in cases involving a family history of VTE [61]. Hereditary thrombophilia does not significantly increase the risk of recurrence (relative risk from 1.4-2.5, depending on the type of mutation
[61]), and anticoagulation treatment should be stopped after 3 months in the absence of risk factors such as cancer. American guidelines also propose anticoagulation cessation after 3 months [3]. European guidelines propose individual assessments of the risks of recurrence and major bleeding in order to decide on whether anticoagulation treatment should continue [2]. In the present case, we chose to screen for thrombophilia and cancer because the thrombosis was unprovoked and located in an unusual site. The patient's borderline age was also taken into account in accordance with an algorithm proposed by Connors [5].

In our review, only $8 \%(4 / 48)$ of patients with IJV thrombosis had an inherited coagulopathy, a low prevalence also seen among Caucasians if patients from Japan, Sri Lanka, India, Jordan, Israel, Turkey, and Saudi Arabia are excluded from the review. Paraneoplastic disease was far more common than inherited coagulopathy, affecting one third of patients (16/48). Thus, an active workup for oncological diseases is of the utmost importance in unprovoked IJV thrombosis.

\section{Treatment of IJV thrombosis}

There are no specific guidelines for the treatment of IJV thrombosis. Treatment is often based, by analogy, on guidelines [2, 3] for upper-limb thrombosis (Tables 1 and 3). Initial treatment (5-21 days following diagnosis) consists of parenteral therapy with low molecular weight heparin (or unfractionated heparin) with a transition using vitamin $\mathrm{K}$ antagonists. The alternative therapy for non-cancer patients is high-dose direct oral anticoagulants. Treatment duration is at least 3 months, with possible long-term anticoagulation depending on the cause of thrombosis [2]. To date, no randomized clinical trials have evaluated anticoagulation for upper extremity deep-vein thrombosis. The only ongoing research is a prospective clinical study assessing oral apixaban for the treatment of upper extremity deep-vein thrombosis (including IJV thrombosis). However, to the best of our knowledge, no results have been published yet [62]. The majority of cases in our literature review used unfractionated heparin $(26 / 40 ; 65 \%)$, usually in association with an oral anticoagulant (19/40; 47.5\%). Treatment duration varied from 2 weeks to 6 months for non-paraneoplastic cases (Table 3).

\section{Follow-up of IJV thrombosis}

No specific guidelines exist for IJV thrombosis followup. Gbaguidi et al. used a venous ultrasound scan at three and 6 months. Boedeker et al. [55] proposed an ultrasound scan each month until 6 months of follow-up.

The management of internal jugular vein thrombosis is heterogenous and currently based on the management 
Table 3 Patient characteristics from the literature review (see text for details)

\begin{tabular}{|c|c|}
\hline Median age & 51 years old (16-88 y.o.) \\
\hline \multirow[t]{3}{*}{ Sex } & F: $26 / 48$ (54.2\%) \\
\hline & M: 16/48 (33.3\%) \\
\hline & Unknown: 6/48 (12.5\%) \\
\hline Number of countries & 17 \\
\hline \multirow{6}{*}{$\begin{array}{l}\text { Modality of diagnostic } \\
\text { imaging }\end{array}$} & US: $7 / 48$ (14.6\%) \\
\hline & CT: $11 / 48$ (22.9\%) \\
\hline & US + CT: 19/48 (39.5\%) \\
\hline & US + MRI: 2/48 (4.2\%) \\
\hline & US + CT + MRI: 2/48 (4.2\%) \\
\hline & $\begin{array}{l}\text { Other or unknown modality: } 7 / 48 \\
(14.6 \%)\end{array}$ \\
\hline \multirow[t]{4}{*}{ Type of treatment } & Heparin only: 7/40 (17.5\%) \\
\hline & $\begin{array}{l}\text { Heparin + oral anticoagulant: 19/40 } \\
(47.5 \%)\end{array}$ \\
\hline & Oral anticoagulant only: 3/40 (7.5\%) \\
\hline & Other or unknown: 11/40 (27.5\%) \\
\hline \multirow[t]{3}{*}{ Type of oral anticoagulant } & Vitamin K antagonists: 18/22 (81.8\%) \\
\hline & Direct oral anticoagulants: $3 / 22$ (13.6\%) \\
\hline & Unknown: 1/22 (4.6\%) \\
\hline \multirow[t]{5}{*}{ Treatment duration } & 3 months: $3 / 48$ (6.25\%) \\
\hline & 6 months: $3 / 48$ (6.25\%) \\
\hline & Long-term: 5/48 (10.4\%) \\
\hline & Other: 4/48 (8.3\%) \\
\hline & Unknown: 33/48 (68.8\%) \\
\hline \multirow[t]{5}{*}{ Complications } & Pulmonary embolism: $3 / 48$ (6.25\%) \\
\hline & Neurological complication: 0/48 (0\%) \\
\hline & Recurrent thrombosis: 2/48 (4.15\%) \\
\hline & Extension of thrombosis: 1/48 (2.1\%) \\
\hline & No complication: 42/48 (87.5\%) \\
\hline
\end{tabular}

Abbreviations: $F$ female, $M$ male, US ultrasound, $C T$ computed tomography, MRI magnetic resonance imaging

of lower extremity deep-vein thrombosis, with a low rate of complications. The lack of guidelines and large series means that the modalities of diagnosis and treatment type and duration are variable. Given the low prevalence of IJV thrombosis, large, randomized studies would be hard to carry out. Data from our literature review suggest that treatments could tend towards those used for lower limb deep-vein thrombosis, but that the modalities of diagnosis and the duration of treatment and followup should be clarified.

\section{Abbreviations}

ARDS: Acute respiratory distress syndrome; BID: Bowel inflammatory disease; COPD: Chronic obstructive pulmonary disease; $\mathrm{CT}$ : Computed tomography; ENT: Ear, nose, and throat; IJV: Internal jugular vein; Jo1: Antihistidyl transfer-
RNA synthetase antibodies; MRI: Magnetic resonance imaging; NSCLC: Nonsmall cell lung cancer; OHS: Ovarian hyperstimulation syndrome; RNP: Antiribonucleoprotein antibodies; SSA: Anti-Sjögren's syndrome type A antibodies; SSB: Anti-Sjögren's syndrome type B antibodies; Scl70: Antiscleroderma antibodies; Sm: Anti-Smith antibodies; US: Ultrasound; VTE: Venous thromboembolism

\section{Acknowledgements \\ None.}

\section{Authors' contributions}

LP contributed significantly to conceptualization, investigation, writing the original draft, reviewing, and editing. $\mathrm{LI}$ and JD contributed to data analysis, resources, visualization, and validation. GJ contributed significantly to conceptualization, validation and supervision, project administration, reviewing, and editing. All authors approved the submitted version.

\section{Funding}

No funding to declare.

\section{Availability of data and materials}

All data generated or analyzed during this study are included in this published article.

\section{Consent for publication}

The patient provided her written informed consent for the case report to be published.

\section{Competing interests}

The authors declare that they have no competing interests.

\section{Author details}

'Department of Internal Medicine, Neuchâtel Hospital Network, Rue de la Maladière 45, CH-2000 Neuchâtel, Switzerland. ${ }^{2}$ Department of Internal Medicine, University of Lausanne, Lausanne, Switzerland. ${ }^{3}$ Brigham and Women's Hospital, Harvard Medical School, Boston, MA, USA. ${ }^{4}$ Department of Internal Medicine, Geneva University Hospitals (HUG), Gabrielle-Perret-Gentil 4, CH-1205 Geneva, Switzerland.

Received: 30 August 2020 Accepted: 29 October 2020

Published online: 06 January 2021

\section{References}

1. Raskob GE, Angchaisuksiri P, Blanco AN, et al. Thrombosis: a major contributor to global disease burden. Arterioscler Thromb Vasc Biol. 2014;34: 2363-71.

2. Mazzolai L, Aboyans V, Ageno W, et al. Diagnosis and management of acute deep vein thrombosis: a joint consensus document from the European Society of Cardiology working groups of aorta and peripheral vascular diseases and pulmonary circulation and right ventricular function. Eur Heart J. 2018;39:4208-18.

3. Kearon C, AkI EA, Comerota AJ, et al. Antithrombotic therapy for VTE disease: antithrombotic therapy and prevention of thrombosis, 9th ed: American College of Chest Physicians Evidence-Based Clinical Practice Guidelines. Chest. 2012;141:e419S-96S.

4. Solomon DH, Kavanaugh AJ, Schur PH. Evidence-based guidelines for the use of immunologic tests: antinuclear antibody testing. Arthritis Care Res. 2002;47:434-44.

5. Connors JM. Thrombophilia testing and venous thrombosis. N Engl J Med. 2017;377:1177-87.

6. Lip GYH, Frison L, Halperin $\mathrm{JL}$, et al. Comparative validation of a novel risk score for predicting bleeding risk in anticoagulated patients with atrial fibrillation: the HAS-BLED (hypertension, abnormal renal/liver function, stroke, bleeding history or predisposition, labile INR, elderly, drugs/alcohol concomitantly) score. J Am Coll Cardiol. 2011;57:173-80.

7. Algoblan D, AlAitah L, Alotaibi AM. Internal Jugular and Subclavian Vein Thrombosis in a Post-liver Transplant Patient. Cureus. 2020;12:e6557.

8. Pratt DN, Patterson KC, Quin K. Venous thrombosis after nitrous oxide abuse, a case report. J Thromb Thrombolysis. 2020;49:501-3.

9. Agrawal A, Bajaj D, Ruben M, et al. Idiopathic Internal Jugular Vein and Subclavian Vein Thrombosis: A Rare Case Report. Cureus. 2019;11:e4005. 
10. Hahn J, Nordmann-Kleiner M, Hoffmann TK, et al. Thrombosis of the internal jugular vein in the ENT-department - Prevalence, causes and therapy: A retrospective analysis. Auris Nasus Larynx. 2019;46:624-9.

11. Matsuda W, Noguchi S, Fujiyama F. Pseudotumor cerebri and lung cancerassociated jugular vein thrombosis: Role of anatomical variations of torcular herophili. eNeurologicalSci. 2018;13:18-20.

12. Al-Zoubi NA. Spontaneous internal jugular vein thrombosis as primary presentation of antiphospholipid syndrome: case report. Vasc Health Risk Manag. 2018;14:153-5.

13. Jendoubi A. Incidental detection of spontaneous floating internal jugular vein thrombosis with acute pulmonary embolism. Saudi J Anaesth. 2017;11: 238-9.

14. Toratani M, Hayashi A, Nishiyama N, et al. Thrombosis in an Internal Jugular Vein and an Upper Limb Deep Vein Treated with Edoxaban. Intern Med Tokyo Jpn. 2017;56:1053-5.

15. Nomura T, Kato T, Keira N, et al. Idiopathic Internal Jugular Vein Thrombosis as Embolic Origin. Intern Med Tokyo Jpn. 2016;55:847-8.

16. Bandara AR, Wimalarathna $H$, Kalupahana $R$, et al. Internal jugular venous thrombosis due to Trousseau's syndrome as the presenting feature of metastatic prostate carcinoma: a case report. J Med Case Rep. 2016;10:104.

17. Efe SC, Poci N, Unkun T, et al. Nineteen-year-old female with idiopathic thrombosis of the internal jugular vein. Perfusion. 2015;30:341-4.

18. Onishi A, Inoue $M$, Imai T, et al. Nephrotic syndrome complicated with deep venous thrombosis in the upper extremities. Case Rep Nephrol Dial. 2015;5:1-5.

19. van den Broek R, van Balen M, Blaauwgeers J, et al. A 28-year-old pregnant woman with a very rare cause of jugular vein thrombosis. Neth J Med. 2014:72:224-6.

20. Altıntaş $\mathrm{O}$, Gürsoy $A E$, Baran $\mathrm{G}$, et al. Bilateral jugular vein and sigmoid sinus thrombosis related to an inherited coagulopathy: an unusual presentation. Case Rep Vasc Med. 2014;2014:873402.

21. Ghatak T, Singh RK, Baronia AK. Spontaneous central vein thrombosis in a patient with activated protein $C$ resistance and dengue infection: An association or causation? J Anaesthesiol Clin Pharmacol. 2013;29: 547-9.

22. Papay $P$, Miehsler $W$, Tilg $H$, et al. Clinical presentation of venous thromboembolism in inflammatory bowel disease. J Crohns Colitis. 2013;7: 723-9.

23. Kunimasa K, Korogi Y, Okamoto Y, et al. Spontaneous internal jugular vein thrombosis associated with lung cancer. Intern Med Tokyo Jpn. 2013;52: 1849 .

24. Honma H, Ohno T, Matsuzaki T, et al. Idiopathic internal jugular vein thrombosis in a patient with severe dizziness. J Echocardiogr. 2011;9: 119-20.

25. Ishida A, Matsuo S, Niimura K, et al. Cervical spontaneous spinal epidural hematoma with internal jugular vein thrombosis. J Neurosurg Spine. 2011;15: 187-9.

26. Gbaguidi X, Janvresse A, Benichou J, et al. Internal jugular vein thrombosis: outcome and risk factors. QJM Mon J Assoc Physicians. 2011;104:209-19.

27. Serinken $M$, Karcioglu O, Korkmaz A. Spontaneous internal jugular vein thrombosis: a case report. Kaohsiung J Med Sci. 2010;26:679-81.

28. Snijders MP, Morsink M, van Spronsen DJ, et al. Internal jugular vein thrombosis as paraneoplastic syndrome of primary ovarian non-Hodgkin's Iymphoma. Eur J Gynaecol Oncol. 2010;31:675-8.

29. Handley TPB, Miah MS, Majumdar S, et al. Collet-sicard syndrome from thrombosis of the sigmoid-jugular complex: a case report and review of the literature. Int J Otolaryngol. 2010. Epub ahead of print 2010. https://doi.org/10.1155/2010/203587.

30. Leibman $Y$, Ayalon M, Steiner IP. Internal Jugular Venous Thrombosis After in Vitro Fertilization. J Emerg Med. 2009;37:29-31.

31. Chlumský J, Havlín J. Spontaneous jugular vein thrombosis. Acta Cardiol. 2009;64:689-91.

32. Pata YS, Ünal M, Gülhan S. Internal jugular vein thrombosis due to distant malignancies: two case reports and literature review. J Laryngol Otol. 2008; 122:318-20.

33. Mori A, Ibata M, Mashiko S, et al. Long-term administration of a lowmolecular-weight heparin contributed to successful treatment in a patient with primary mediastinal large B-cell lymphoma and venous thromboembolism. Clin Appl Thromb Off J Int Acad Clin Appl Thromb. 2008;14:468-71.
34. Kikuchi M, Yamamoto E, Shiomi Y, et al. Case report: internal and external jugular vein thrombosis with marked accumulation of FDG. Br J Radiol. 2004;77:888-90

35. Cheang PP, Fryer J, Ayoub O, et al. Spontaneous bilateral internal jugular vein thrombosis: a sign of metastasis. J Laryngol Otol. 2004;118:570-2.

36. Unsal EE, Karaca C, Ensarí S. Spontaneous internal jugular vein thrombosis associated with distant malignancies. Eur Arch Oto-Rhino-Laryngol Off J Eur Fed Oto-Rhino-Laryngol Soc EUFOS Affil Ger Soc Oto-Rhino-Laryngol - Head Neck Surg. 2003;260:39-41.

37. Khandekar AA, Kumbhalkar SD, Salkar HR, et al. Protein S deficiency presenting as deep vein thrombosis--a case report. Angiology. 2003;54:605-8.

38. Thomas RV, Reid W, Perry DJ. Internal jugular vein thrombosis following invitro fertilization in a woman with protein $\mathrm{S}$ deficiency and heterozygosity for the prothrombin 3' UTR mutation, despite anticoagulation with heparin. Blood Coagul Fibrinolysis Int J Haemost Thromb. 2001;12:487-9.

39. Van den Noortgate N, Michielsen W, Afschrift M, et al. Spontaneous internal jugular vein thrombosis: primary manifestation of a colorectal adenocarcinoma in a very old woman. Acta Clin Belg. 2000;55:94-6.

40. Todros T, Carmazzi CM, Bontempo S, et al. Spontaneous ovarian hyperstimulation syndrome and deep vein thrombosis in pregnancy: case report. Hum Reprod Oxf Engl. 1999;14:2245-8.

41. Kalan A, Tariq M, Harar RP, et al. Spontaneous internal jugular vein thrombosis and recurrent laryngeal nerve palsy: a rare simultaneous presentation of an occult malignant neoplasm. J Laryngol Otol. 1996;110:1166-8.

42. Holland AJ, Childs PA, Beilin J, et al. Spontaneous thrombosis of the internal jugular vein as the initial presentation of the primary antiphospholipid syndrome. Aust N Z J Surg. 1996;66:854-5.

43. Hines JF, Tucker A, Grendys EC, et al. Spontaneous preoperative internal jugular and subclavian vein thrombosis associated with an early-stage synchronous ovarian/endometrial malignancy. Gynecol Oncol. 1995;56:298-301.

44. Langlieb AM, Dunton CJ, Carlson JA. Spontaneous internal jugular vein thrombosis associated with leiomyosarcoma of the omentum. Gynecol Oncol. 1992:47:125-6.

45. Carrington BM, Adams JE. Jugular vein thrombosis associated with distant malignancy. Postgrad Med J. 1988;64:455-8.

46. Kennedy KS, Tami TA, Friedman JC, et al. Spontaneous thrombosis of the internal jugular vein. Ann Otol Rhinol Laryngol. 1987;96:222-4.

47. Flinterman LE, Van Der Meer FJM, Rosendaal FR, et al. Current perspective of venous thrombosis in the upper extremity. J Thromb Haemost JTH 2008;6: $1262-66$.

48. Shatzel JJ, O'Donnell M, Olson SR, et al. Venous thrombosis in unusual sites: A practical review for the hematologist. Eur J Haematol 2019;102:53-62.

49. Binnebösel $M$, Grommes J, Junge $K$, et al. Internal jugular vein thrombosis presenting as a painful neck mass due to a spontaneous dislocated subclavian port catheter as long-term complication: a case report. Cases J. 2009;2:7991.

50. Weaver LA, Kanter CR, Costantino TG. Effort thrombosis provoked by saxophone performance. J Emerg Med. 2019:56:323-6.

51. Ilhan $E$, Ture M, Yilmaz C, et al. Subclavian vein thrombosis extending into the internal jugular vein: Paget-von Schroetter syndrome. J Clin Med Res. 2009:1:178-80.

52. Sennström M, Rova K, Hellgren $M$, et al. Thromboembolism and in vitro fertilization - a systematic review. Acta Obstet Gynecol Scand. 2017:96:1045-52.

53. Hellgren M. Hemostasis during normal pregnancy and puerperium. Semin Thromb Hemost. 2003:29:125-30.

54. Kodama H, Fukuda J, Karube $H$, et al. Characteristics of blood hemostatic markers in a patient with ovarian hyperstimulation syndrome who actually developed thromboembolism. Fertil Steril. 1995;64:1207-9.

55. Boedeker CC, Ridder GJ, Weerda N, et al. Etiology and therapy of the internal jugular vein thrombosis. Laryngorhinootologie. 2004;83:743-9.

56. Douma RA, Mos ICM, Erkens PMG, et al. Performance of 4 clinical decision rules in the diagnostic management of acute pulmonary embolism: a prospective cohort study. Ann Intern Med. 2011;154:709-18.

57. Righini M, Perrier A, De Moerloose $\mathrm{P}$, et al. D-dimer for venous thromboembolism diagnosis: 20 years later. J Thromb Haemost JTH. 2008;6: 1059-71.

58. Middeldorp S, van Hylckama Vlieg A. Does thrombophilia testing help in the clinical management of patients? Br J Haematol. 2008;143:321-35.

59. Rees DC. The population genetics of factor $V$ Leiden (Arg506Gln). Br J Haematol. 1996:95:579-86. 
60. Middeldorp S, Henkens CMA, Koopman MMW, et al. The incidence of venous thromboembolism in family members of patients with factor $\mathrm{V}$ Leiden mutation and venous thrombosis. Ann Intern Med. 1998;128:15-20.

61. Pruthi RK. Optimal utilization of thrombophilia testing. Int J Lab Hematol. 2017:39:104-10

62. Woller SC, Stevens SM, Johnson SA, et al. Apixaban for Routine Management of Upper Extremity Deep Venous Thrombosis (ARM-DVT): Methods of a prospective single-arm management study. Res Pract Thromb Haemost 2019;3:340-48.

\section{Publisher's Note}

Springer Nature remains neutral with regard to jurisdictional claims in published maps and institutional affiliations.

Ready to submit your research? Choose BMC and benefit from:

- fast, convenient online submission

- thorough peer review by experienced researchers in your field

- rapid publication on acceptance

- support for research data, including large and complex data types

- gold Open Access which fosters wider collaboration and increased citations

- maximum visibility for your research: over $100 \mathrm{M}$ website views per year

At $\mathrm{BMC}$, research is always in progress.

Learn more biomedcentral.com/submissions 